\title{
Transcutaneous $\mathrm{CO}_{2}$ versus end-tidal $\mathrm{CO}_{2}$ in neonates and infants undergoing surgery: a prospective study
}

This article was published in the following Dove Press journal: Medical Devices: Evidence and Research

\author{
Arvind Chandrakantan' \\ Ronald Jasiewicz ${ }^{2}$ \\ Ruth A Reinsel ${ }^{3}$ \\ Kseniya Khmara ${ }^{2}$ \\ Jonathan Mintzer ${ }^{4}$ \\ Joseph D DeCristofaro ${ }^{4}$ \\ Zvi Jacob ${ }^{2}$ \\ Peggy Seidman ${ }^{5}$ \\ 'Department of Anesthesiology \& \\ Pediatrics, Texas Children's Hospital, \\ Houston, TX, USA; ${ }^{2}$ Department of \\ Anesthesiology, Stony Brook University \\ Hospital, Stony Brook, NY, USA; \\ ${ }^{3}$ Department of Neurology, Stony Brook \\ University Hospital, Stony Brook, NY, \\ USA; ${ }^{4}$ Department of Neonatology \& \\ Pediatrics, Stony Brook University \\ Hospital, Stony Brook, NY, USA; \\ ${ }^{5}$ Department of Anesthesiology \& \\ Pediatrics, UH Rainbow Babies and \\ Children's Hospital, Cleveland, OH, USA
}

Correspondence: Arvind Chandrakantan Department of Anesthesiology \& Pediatrics, Texas Children's Hospital, 662I Fannin Street, Houston, TX 77030, USA Tel +I 8328244100

Email chandrak@bcm.edu

\begin{abstract}
Aim: End-tidal $\mathrm{CO}_{2}\left(\mathrm{Et}_{\mathrm{CO} 2}\right)$ is the standard in operative care along with pulse oximetry for ventilation assessment. It is known to be less accurate in the infant population than in adults. Many neonatal intensive care units (NICU) have converted to utilizing transcutaneous $\mathrm{CO}_{2}$ (tcP $\left.\mathrm{P}_{\mathrm{CO} 2}\right)$ monitoring. This study aimed to compare perioperative $\mathrm{Et}_{\mathrm{CO} 2}$ to $\mathrm{tcP}_{\mathrm{CO} 2}$ in the pediatric perioperative population specifically below $10 \mathrm{~kg}$, which encompasses neonates and some infants.
\end{abstract}

Methods: After IRB approval and parental written informed consent, we enrolled neonates and infants weighing less than $10 \mathrm{~kg}$, who were scheduled for elective surgery with endotracheal tube under general anesthesia. $\mathrm{P}_{\mathrm{CO} 2}$ was monitored with $\mathrm{Et}_{\mathrm{CO} 2}$ and with tc $\mathrm{P}_{\mathrm{CO} 2}$. Venous blood gas $\left(\mathrm{Pv}_{\mathrm{CO} 2}\right)$ samples were drawn at the end of the anesthetic. We calculated a mean difference of $\mathrm{Et}_{\mathrm{CO} 2}$ minus $\mathrm{Pv}_{\mathrm{CO} 2}$ (Delta $\mathrm{Et}_{\mathrm{CO} 2}$ ), and $\mathrm{tc}_{\mathrm{CO} 2}$ minus $\mathrm{Pv}_{\mathrm{CO} 2}$ (Delta $\mathrm{tcP}_{\mathrm{CO} 2}$ ) from end-of-case measurements. The mean differences in the NICU and nonNICU patients were compared by t-tests and Bland-Altman analysis.

Results: Median age was 10.9 weeks, and median weight was $4.4 \mathrm{~kg}$. NICU (n=6) and nonNICU ( $\mathrm{n}=14$ ) patients did not differ in $\mathrm{Pv}_{\mathrm{CO} 2}$. Relative to the $\mathrm{Pv}_{\mathrm{CO} 2}$, the Delta $\mathrm{Et}_{\mathrm{CO} 2}$ was much greater in the NICU compared to the non-NICU patients $(-28.1$ versus $-9.8, \mathrm{t}=3.912$, $18 \mathrm{df}, P=0.001)$. Delta $\mathrm{tcP}_{\mathrm{CO} 2}$ was close to zero in both groups. Although both measures obtained simultaneously in the same patients agreed moderately with each other $(r=0.444$, $18 \mathrm{df}, P=0.05$ ), Bland-Altman plots indicated that the mean difference (bias) in $\mathrm{Et}_{\mathrm{CO} 2}$ measurements differed significantly from zero $(P<0.05)$.

Conclusions: $\mathrm{Et}_{\mathrm{CO} 2}$ underestimates $\mathrm{Pv}_{\mathrm{CO} 2}$ values in neonates and infants under general anesthesia. $\mathrm{TcP}_{\mathrm{CO} 2}$ closely approximates venous blood gas values, in both the NICU and non-NICU samples. We, therefore, conclude that $\mathrm{tcP}_{\mathrm{CO} 2}$ is a more accurate measure of operative $\mathrm{Pv}_{\mathrm{CO} 2}$ in infants, especially in NICU patients.

Keywords: infant, newborn, end-tidal $\mathrm{CO}_{2}$, blood gas monitoring-transcutaneous, intensive care monitoring- neonatal, ASA monitoring standards

\section{Introduction}

Transcutaneous $\mathrm{CO}_{2}$ monitoring ( $\left(\mathrm{tc} \mathrm{P}_{\mathrm{CO} 2}\right)$ is a well-described non-invasive method to trend ventilation in neonates and is validated as accurate through all age groups. Recent literature has evaluated the relative efficacy of transcutaneous $\mathrm{CO}_{2}\left(\mathrm{tcP}_{\mathrm{CO} 2}\right)$ compared to end-tidal $\mathrm{CO}_{2}\left(\mathrm{Et}_{\mathrm{CO} 2}\right)$ monitoring as a reflection of arterial $\mathrm{CO}_{2}\left(\mathrm{~Pa}_{\mathrm{CO} 2}\right)$. Publications relating to use in infants and children with respiratory failure, ${ }^{1}$ congenital heart disease, ${ }^{2}$ and one lung ventilation ${ }^{3}$ have demonstrated improved correlation 
between $\mathrm{Pa}_{\mathrm{CO} 2}$ with tcP $\mathrm{P}_{\mathrm{CO} 2}$ as compared to correlation of $\mathrm{Pa}_{\mathrm{CO} 2}$ with

$\mathrm{Et}_{\mathrm{CO} 2}$; however, controversy exists. Two recent reviews suggest that $\mathrm{tc}_{\mathrm{CO} 2}$ should be used as an adjunct to endtidal $\mathrm{CO}_{2} \cdot{ }^{4,5}$ One study which showed close correlation of $\mathrm{Et}_{\mathrm{CO} 2}$ with $\mathrm{Pa}_{\mathrm{CO} 2}$ recommends $\mathrm{Et}_{\mathrm{CO} 2}$ usage for longitudinal monitoring in the neonatal intensive care unit (NICU); ${ }^{6}$ data from a more heterogeneous intraoperative cohort suggest that tc $\mathrm{P}_{\mathrm{CO} 2}$ may be more accurate. ${ }^{7}$ This non-invasive infant study uses $\mathrm{Pv}_{\mathrm{CO} 2}$ as the surrogate for $\mathrm{Pa}_{\mathrm{CO} 2}$.

The standard of care for monitoring respiratory status during anesthesia has been end-tidal $\mathrm{CO}_{2}\left(\mathrm{Et}_{\mathrm{CO} 2}\right)$ and pulse oximetry. While this methodology is well established in operative care, $\mathrm{Et}_{\mathrm{CO} 2}$ is known to be less accurate in the neonatal population. The sampling flow rate on the $\mathrm{Et}_{\mathrm{CO} 2}$ in relation to the tidal volume and total flow used to ventilate extremely low birth weight infants provides ambiguous data. In addition, $\mathrm{Et}_{\mathrm{CO} 2}$ is not feasible in high-frequency oscillators or jet ventilators as the volume of each breath is less than dead space. Many neonatal intensive care units and pediatric intensive care units (PICU) utilize tc $\mathrm{P}_{\mathrm{CO} 2}$ as a primary means of $\mathrm{Pa}_{\mathrm{CO} 2}$ monitoring. Adequate direct comparisons of the two monitors are not available. Based on preliminary data in neonates, our null hypothesis was that there would be no difference between venous $\mathrm{CO}_{2}$ as measured by end-tidal and transcutaneous methods.

\section{Methods}

\section{IRB approval and informed consent}

This study was approved by the Stony Brook University Committee on Research Involving Human Patients. Parents were approached in person or by telephone by a physician or the study coordinator at least one day in advance of scheduled operative procedures. All study procedures were further explained and written informed consent was obtained on the day of surgery.

\section{Research site}

This study was conducted in the main operating room of an academic tertiary care university hospital with a level 3 NICU (Regional Perinatal Center) between April 2015 and October 2016.

\section{Sample size requirements}

The estimated sample size is based on a correlational analysis. We assume a relationship of at least moderate magnitude between the two techniques for estimation of
$\mathrm{p}_{\mathrm{CO} 2}$. Estimation of the required sample size is complicated by the range of values seen in our preliminary observations. Pearson correlations between $\mathrm{T}_{\mathrm{CO} 2}$ and $\mathrm{Et}_{\mathrm{CO} 2}$ ranged from +0.59 to -0.74 . Disregarding the direction of the relationship (direct or inverse), the absolute values of 0.6 to 0.7 suggest a "large" effect size. We can thus estimate sample sizes under the assumption of a large effect size, rho $=0.5$. For $80 \%$ power at alpha level $=0.05$ using a 2-tailed analysis, 26 subjects would be required.

\section{Study sample}

Infants up to 12 months of age and under $10 \mathrm{~kg}$ in weight who required an elective surgery with general anesthesia were eligible for the study. Patients were excluded if they required emergency surgery, if they were receiving anesthesia without an endotracheal tube (ETT) or if the parents were unable to read or understand the consent form in either English or Spanish.

\section{Equipment}

End-tidal $\mathrm{CO}_{2}\left(\mathrm{Et}_{\mathrm{CO} 2}\right)$ was measured via the sidestream (diverting) sampling device (Medline 3m 0.06 ID) on the anesthesia machine (GE Aisys Datex-Ohmeda). Transcutaneous $\mathrm{CO}_{2}\left(\mathrm{tcP}_{\mathrm{CO} 2}\right)$ was measured using the SenTec Digital Monitoring System (SDMS) manufactured by SenTec AG (Therwil, Switzerland; www.sentec.com ). This is an FDA-approved clinical monitoring device that is used in NICUs globally. $\mathrm{TcP}_{\mathrm{CO} 2}$ measurements were recorded with the $\mathrm{V}-\mathrm{Sign}^{\mathrm{TM}}$ Sensor 2, under software version MPB-SW:V05.03.02/SMB-SW:V07.03.1.The sensor head is extremely lightweight (less than $2.9 \mathrm{~g}$ ) and small $(14 \mathrm{mmx} 9 \mathrm{~mm})$ and is applied to the skin using an adhesive ring specially designed for sensitive, fragile skin. $\mathrm{O}_{2}$ saturation and pulse rate were obtained from our standard intraoperative monitor. $\mathrm{TcP}_{\mathrm{CO} 2}$ data reported here were manually recorded from the SDMS visual display and do not reflect the tc $\mathrm{P}_{\mathrm{CO} 2}$ values corrected for residual drift (obtainable via retrospective data download), as would be seen in real-time. The monitor was warmed up and calibrated by the study team the morning that an appropriate OR case was identified and consented. Membranes were changed per routine maintenance following manufacturer guidelines every 40 days.

\section{Procedures}

In the OR, the $\mathrm{tcP}_{\mathrm{CO} 2} \mathrm{~V}$-Sign ${ }^{\mathrm{TM}}$ Sensor 2 with Multi-Site Attachment Ring was applied along with standard ASA monitors which are 3 lead electrocardiogram (EKG), 
non-invasive blood pressure cuff (NIBP), pulse oximetry, and temperature probe. In most cases, the sensor was placed on the forehead. If that site was not available, it was placed as close to the core of the body as the surgical site and surgical preparation allowed in concordance with manufacturer recommendations. To ensure optimal recording of tc $\mathrm{P}_{\mathrm{CO} 2}$, every effort was made to follow manufacturer recommendations for sensor placement (see Figure 1).

After baseline vital signs, the patients were anesthetized using either standard mask induction with sevoflurane and an IV was placed if one was not already in place or the patient was induced with the IV and then ETT placed after IV induction unless the child arrived intubated. Vital signs (cardiac rhythm, heart rate, respiratory rate, blood pressure, pulse oximetry, temperature) were recorded every 5 mins as per standard of care. Operative events were noted on the data sheet including: induction, intubation, neuraxial block, positioning for surgery, incision, closure, and extubation.

$\mathrm{TcP}_{\mathrm{CO} 2}$ was monitored concurrently with $\mathrm{Et}_{\mathrm{CO} 2}$, with respiratory mode noted (spontaneous vs controlled). The anesthesiologist delivering anesthesia was blinded to the readings of the $\mathrm{tcPCO}_{2}$ monitor and provided intraoperative care using standard monitors including $\mathrm{Et}_{\mathrm{CO} 2}$ to guide operative management. A separate data sheet was utilized to document the TCOM readings and note significant events and was blinded to the anesthesiology team caring for the patient.

\section{Blood samples}

Prior to extubation, a venous blood sample was obtained or a capillary blood gas was obtained from a heel or thumb stick and analyzed for $\mathrm{Pv}_{\mathrm{CO} 2}$. Blood gas parameters including $\mathrm{pH}$, partial pressure of oxygen $\left(\mathrm{p}_{\mathrm{v}} \mathrm{O}_{2}\right)$, bicarbonate concentration $\left(\mathrm{HCO}_{3}-\right)$, and base excess $(\mathrm{BE})$ were recorded.

\section{Data analysis}

For each patient, we calculated a mean difference of Delta $\mathrm{Et}_{\mathrm{CO} 2}\left(\mathrm{Et}_{\mathrm{CO} 2}\right.$ minus $\left.\mathrm{Pv}_{\mathrm{CO} 2}\right)$, and Delta tcP $\mathrm{P}_{\mathrm{CO} 2}\left(\mathrm{tcP}_{\mathrm{CO} 2}\right.$ minus $\mathrm{Pv}_{\mathrm{CO} 2}$ ) from end-of-case measurements, matched as closely as possible to the time of venous blood gas sampling. Independent t-tests were used to compare the mean differences between NICU and non-NICU patients. In view of the small sample size, we repeated these tests with a nonparametric Mann-Whitney U-test, which is not dependent on normally distributed data. Within-patient comparisons between $\mathrm{Et}_{\mathrm{CO} 2}$ and $\mathrm{tcP}_{\mathrm{CO} 2}$ measures were made using the Wilcoxon signed ranks test. We considered a $P$-value of $<0.05$ as significant. All statistical testing was performed using IBM SPSS v22 (IBM, Armonk, NY). Continuous variables were analyzed using parametric and/or nonparametric testing based on the presence or absence of normal distributions, and were done on an individual variable basis to ensure scientific rigor. All values are in $\mathrm{mm} \mathrm{Hg}$ unless otherwise indicated.
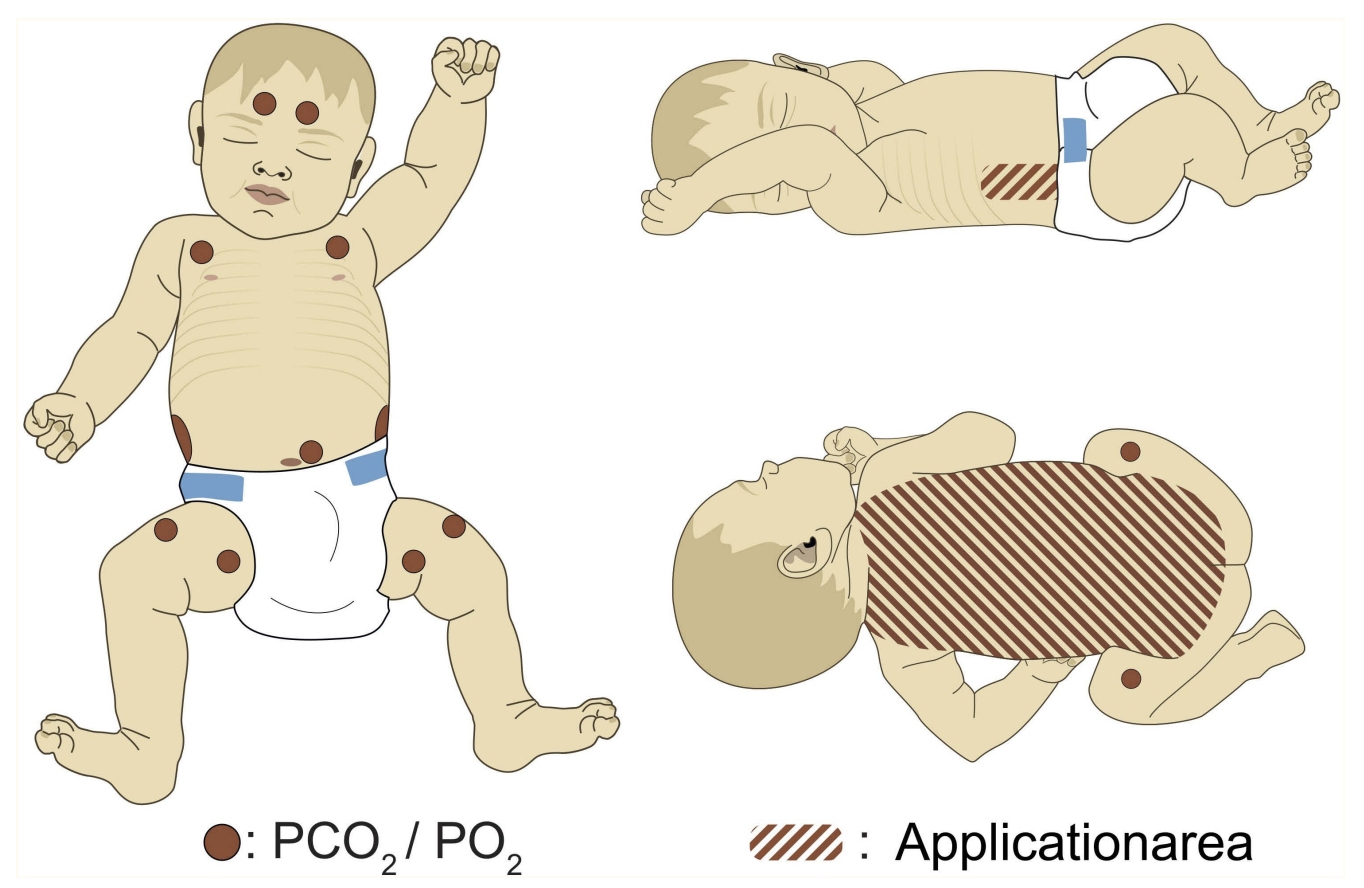

Figure I Manufacturer recommendations for sensor placement in infants, numbered in order of preference (I= high, 3= low). Source: SenTec AG, Therwil, Switzerland (www.sentec.com). 


\section{Agreement between methods of measurement}

$\mathrm{Et}_{\mathrm{CO} 2}$ and $\mathrm{TcP}_{\mathrm{CO} 2}$ were compared to venous blood gas measure of $\mathrm{P}_{\mathrm{CO} 2}$ using the Bland-Altman technique. ${ }^{8,9}$ This wellaccepted graphical technique plots the mean of the two measures versus the difference of the two measures with $95 \%$ limits of agreement. If the two measures agree perfectly, all differences will be zero. The difference of the two measures is termed "bias". One can calculate a $95 \%$ confidence interval around the mean difference (mean $\pm 1.96 *$ standard error of the mean). Statistical significance was defined a priori based on $95 \%$ confidence intervals of mean differences not including a determination of utility (bias of zero) between the two $\mathrm{CO}_{2}$ measurement techniques.

\section{Results}

\section{Patient sample}

A total of 38 patients were enrolled with parental written informed consent. For six patients no data was obtained due to delay or cancellation of surgery, or lack of availability of study staff at the time of surgery. One patient was excluded from analysis due to a protocol deviation (use of laryngeal mask airway). Two patients came to the OR twice, each time as a separate consent, as allowed by our IRB protocol; but only one surgery was used in this analysis to meet statistical assumptions that the observations are independent. The choice of which patients to include was made based on availability of blood gas data at the end of the case. Insufficient data for venous blood gas analysis was obtained at the end of 5 additional cases, and in 4 patients the venous blood gas was obtained post-extubation, leaving no corresponding value for $\mathrm{Et}_{\mathrm{CO} 2}$. This left 20 patients (6 NICU, 14 non-NICU) with concurrent end-tidal and transcutaneous $\mathrm{CO}_{2}$ values for analysis. Characteristics of the patient cohort are given in Table 1. Thirteen out of the 20 patients were intubated with cuffed ETT. The leak was between 15 and $25 \mathrm{~mm} \mathrm{Hg}$ in both groups and no difference in $\mathrm{EtCO}_{2}$ was noted.

The median post-natal age on the day of surgery was 10.9 weeks (range $0.3-47$ weeks). The median weight was $4.45 \mathrm{~kg}$ (range 1.8-9.8 kg). Abdominal surgeries were the most frequent $(n=9)$, followed by cleft lip/palate $(n=3)$, neurological $(n=2)$, orthopedic $(n=2)$, bronchial $(n=1)$, thoracic $(\mathrm{n}=1)$, urological $(\mathrm{n}=1)$, and central venous access $(n=1)$. Within the NICU group $(n=6)$, laparotomies were the most common procedure $(n=3)$. As expected, NICU patients were significantly younger in gestational age $(\mathrm{t}=3.203,17.3 \mathrm{df}, P=0.001)$ and lower in weight $(\mathrm{t}=3.978$,
Table I Characteristics of NICU and non-NICU subjects. For continuous variables, values are mean \pm standard deviation

\begin{tabular}{|l|l|l|}
\hline & $\begin{array}{l}\text { NICU } \\
(\mathbf{n = 6})\end{array}$ & $\begin{array}{l}\text { Non-NICU } \\
(\mathbf{n}=14)\end{array}$ \\
\hline ASA (I/II/III/IV) & $0 / 0 / 2 / 4$ & $2 / 7 / 5 / 0$ \\
Gender & $3 \mathrm{M}, 3 \mathrm{~F}$ & $9 \mathrm{M}, 5 \mathrm{~F}$ \\
Premature at birth (n, \%) & $4(66.7 \%)$ & $4(28.6 \%)$ \\
Post-natal age (weeks) & $6.2+6.8$ & $17.0 \pm 10.8$ \\
Gestational age (weeks) & $38.7 \pm 4.8$ & $51.9 \pm 9.5$ \\
Weight on DOS (kg) & $2.6 \pm 0.5$ & $5.4 \pm 1.7$ \\
Anesthesia time (mins) & $165.3+43.8$ & $147.3+78.7$ \\
\hline
\end{tabular}

Notes: Data presented as mean \pm SD unless otherwise indicated.

Abbreviations: ASA, American Society of Anesthesiologists; DOS, day of surgery; NICU, neo-natal intensive care unit.

$18 \mathrm{df}, P=0.001$ ) than non-NICU patients (see Table 1). Anesthesia time did not differ between groups (see Table 1).

Two infants arrived from the NICU already intubated and were returned to the NICU in the same condition. Three additional neonates were not extubated after surgery and were returned to the NICU intubated. Vasoactive agents were not utilized for any of the patients.

\section{Sensor placement}

For the NICU group, all but one had the V-Sign Sensor 2 placed on the forehead $(n=3)$ or abdomen/chest $(n=2)$. A single baby had the sensor placed on the lower leg, which is a less favorable but accepted position for $t_{c} \mathrm{P}_{\mathrm{CO} 2}$ measurement. Among the non-NICU patients, 8 had the sensor placed on the forehead, 2 on the abdomen/chest, and 4 on the shoulder/back.

\section{Blood gas analysis}

As shown in Table 2, the difference between blood $\mathrm{pH}$ and $\mathrm{PvO}_{2}$ was not statistically significant. However, NICU patients had higher levels of bicarbonate $(\mathrm{t}=-2.813,18 \mathrm{df}$, $P=0.012)$ and lower base excess ( $\mathrm{t}=-2.298,18 \mathrm{df}, P=0.034)$.

Measurement of $P_{\mathrm{CO} 2}$. tc $\mathrm{P}_{\mathrm{CO} 2}$ levels were higher than $\mathrm{Et}_{\mathrm{CO} 2}$ in both populations (see Table 2). $\mathrm{Et}_{\mathrm{CO} 2}$ values in NICU patients did not differ significantly compared to older infants. The mean difference between $\mathrm{Et}_{\mathrm{CO} 2}$ and $\mathrm{Pv}_{\mathrm{CO} 2}$ was significantly greater in NICU patients $(-28.1$ $\pm 12.3)$ vs non-NICU patients $(9.8 \pm 8.3)(\mathrm{t}=3.912,18 \mathrm{df}$, $P=0.001$, see Figure 2 ; $P$-value confirmed by MannWhitney U-test). The mean difference between tcP $\mathrm{P}_{\mathrm{CO} 2}$ and $\mathrm{Pv}_{\mathrm{CO} 2}$ between NICU $(-0.7 \pm 11.2)$ and non-NICU patients (3.0 \pm 9.8$)$ was not significantly different $(\mathrm{t}=-0.733,18 \mathrm{df}$, $P=0.473)$. However, Wilcoxon signed rank tests for related 
Table 2 Blood gas analysis (mean \pm standard deviation) for NICU and non-NICU subjects. Venous blood gas samples were taken at the end of the case

\begin{tabular}{|c|c|c|c|}
\hline & $\begin{array}{l}\text { Neonatal } \\
\text { intensive } \\
\text { care unit } \\
(\mathrm{NICU}) \\
(\mathrm{n}=6)\end{array}$ & $\begin{array}{l}\text { Non- } \\
\text { NICU } \\
(n=\mid 4)\end{array}$ & $\begin{array}{l}P \text {-value for } \\
\text { independent } \\
\text { t-test }\end{array}$ \\
\hline $\begin{array}{l}\text { Venous blood gas } \\
\left(\mathrm{Pv}_{\mathrm{CO} 2}\right)\end{array}$ & $60.1 \pm 9.3$ & $\begin{array}{l}48.9 \\
\pm \mid 4.1\end{array}$ & $P=0.093$ \\
\hline $\begin{array}{l}\text { Transcutaneous CO- } \\
{ }_{2}\left(\mathrm{tcP}_{\mathrm{CO} 2}\right)\end{array}$ & $59.4 \pm 12.7$ & $\begin{array}{l}51.9 \\
\pm 13.1\end{array}$ & $P=0.251$ \\
\hline $\begin{array}{l}\text { End- } \\
\text { tidal } \mathrm{CO}_{2}\left(\mathrm{Et}_{\mathrm{CO} 2}\right)\end{array}$ & $32.0 \pm 12.4$ & $\begin{array}{l}39.1 \\
\pm 10.8\end{array}$ & $P=0.215$ \\
\hline Delta $\left(t \mathrm{CP}_{\mathrm{CO} 2}-\mathrm{Pv}_{\mathrm{CO} 2}\right)$ & $-0.7 \pm 11.2$ & $\begin{array}{l}+3.0 \\
\pm 9.8\end{array}$ & $P=0.473$ \\
\hline $\operatorname{Delta}\left(\mathrm{Et}_{\mathrm{CO}_{2}}-\mathrm{Pv}_{\mathrm{CO} 2}\right)$ & $-28.1 \pm 12.3$ & $\begin{array}{l}-9.8 \\
\pm 8.3\end{array}$ & $P=0.00 I$ \\
\hline $\mathrm{pH}$ & $7.3 \pm 0.1$ & $7.3 \pm 0.1$ & $P=0.518$ \\
\hline $\mathrm{PvO}_{2}$ & $57.6 \pm 14.3$ & $\begin{array}{l}90.3 \\
\pm 59.8\end{array}$ & $P=0.209$ \\
\hline $\mathrm{HCO}_{3}-$ & $26.6 \pm 3.1$ & $\begin{array}{l}22.5 \\
\pm 2.9\end{array}$ & $P=0.012$ \\
\hline $\mathrm{BE}$ & $-0.4 \pm 4.5$ & $\begin{array}{l}-4.0 \\
\pm 2.6\end{array}$ & $P=0.034$ \\
\hline
\end{tabular}

Notes: Indicates $P<0.05$ is generally considered to be statistically significant.

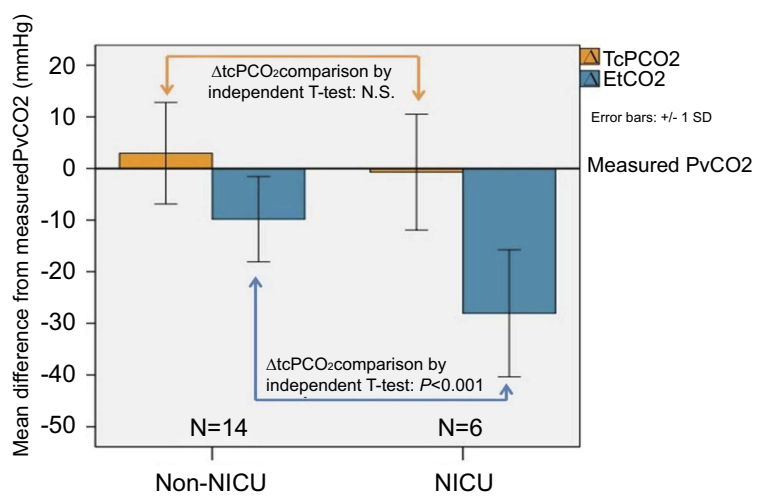

Figure $2 \Delta \mathrm{Et}_{\mathrm{CO} 2}$ and $\Delta \mathrm{TcP}_{\mathrm{CO} 2}$ in $\mathrm{NICU}$ and non-NICU patients. Values are normalized to the measured $\mathrm{Pv}_{\mathrm{CO} 2}$ for each patient, indicated by the zero line on the vertical axis. $\mathrm{TcP}_{\mathrm{CO} 2}$ rather than $\mathrm{Et}_{\mathrm{CO} 2}$ levels closely approximated $\mathrm{Pv}_{\mathrm{CO} 2}$ in both populations. Dark bars: $\mathrm{Et}_{\mathrm{CO} 2}$; light bars: $\mathrm{tcP}_{\mathrm{CO} 2}$. Arrows indicate groups compared for independent-groups $t$-test. A nonparametric test for paired samples was also performed to compare measures of $\Delta \mathrm{Et}_{\mathrm{CO} 2}$ and $\Delta \mathrm{TcP}_{\mathrm{CO} 2}$ within each patient group. This test showed significant differences $(P<0.05)$ between $\mathrm{Et}_{\mathrm{CO} 2}$ and tcP $\mathrm{PO}_{\mathrm{CO}}$ within both $\mathrm{NICU}$ and non-NICU patient groups.

Abbreviations: $\mathrm{PV}_{\mathrm{CO} 2}$, venous blood gas; $\mathrm{tcP}_{\mathrm{CO} 2}$, transcutaneous $\mathrm{CO}_{2}$; $\mathrm{Et}_{\mathrm{CO} 2}$, end-tidal $\mathrm{CO}_{2}$; $\mathrm{NICU}$, neo-natal intensive care unit; N.S., non significant.

samples showed that $\mathrm{tcP}_{\mathrm{CO} 2}$ and $\mathrm{Et}_{\mathrm{CO} 2}$ were significantly different within both groups $(P=0.028$ for NICU and $P=0.001$ for non-NICU patients).

Blood gas results are shown in Table 2. The nonparametric Mann-Whitney U-Test found that venous blood gas was significantly different between the two groups at both the start $(P=0.036)$ and end $(P=0.033)$ of the surgery. By paired $t$-test, these differences were significant only at the start of the case $(\mathrm{t}=-2.620,12 \mathrm{df}, P=0.022)$. NICU and non-NICU patients did not differ in venous blood gas $\mathrm{Pv}_{\mathrm{CO} 2}, \mathrm{tcP}_{\mathrm{CO} 2}$ or $\mathrm{Et}_{\mathrm{CO} 2}$ at the end of the case. Delta $\mathrm{Et}_{\mathrm{CO} 2}$ was much greater in the NICU babies compared to non-NICU patients $(-28.1$ versus $-9.8, \mathrm{t}=3.912,18 \mathrm{df}, P=0.001)$. Delta $\mathrm{tc}_{\mathrm{CO} 2}$ was close to zero in both groups. $\mathrm{TcP}_{\mathrm{CO} 2}$ did not differ significantly from measured $\mathrm{Pv}_{\mathrm{CO} 2}$ in these two patient groups.

\section{Comparison of methods by Bland- Altman analysis}

Figure 3 and Table 3 show $\mathrm{tcP}_{\mathrm{CO} 2}$ and $\mathrm{Et}_{\mathrm{CO} 2}$ compared to the venous blood gas measurement $\left(\mathrm{Pv}_{\mathrm{CO} 2}\right)$ using the BlandAltman technique. Comparing tc $\mathrm{P}_{\mathrm{CO} 2}$ to $\mathrm{Pv}_{\mathrm{CO} 2}$ (Figure $3 \mathrm{~A}$ ), these plots show agreement between measures, with a mean difference (bias) of 1.86 (95\% CI -2.57 to 6.29$)$, in the full sample of 20 patients. The value is similarly low in NICU $(-0.70,95 \% \mathrm{CI}-9.68$ to 8.28$)$ and non-NICU patients $(2.96$, 95\% CI -2.19 to 8.11). Comparing $\mathrm{Et}_{\mathrm{CO} 2}$ to $\mathrm{Pv}_{\mathrm{CO} 2}$ (Figure $3 \mathrm{~B})$, the plots show a much higher bias of -15.29 (95\% CI -20.84 to -9.74$)$ for the full sample, with high variability, especially among NICU patients. The mean bias is nearly three times as high among NICU patients $(-28.07,95 \% \mathrm{CI}$ -37.91 to -18.23$)$ as in the non-NICU group $(-9.82,95 \% \mathrm{CI}$ -14.15 to -5.49$)$. This variability seems to be most pronounced for the average measure of $\left(\mathrm{Et}_{\mathrm{CO} 2}+\mathrm{Pv}_{\mathrm{CO} 2}\right)$ below 40 (see Figure 3B). The standard deviations of the bias are similar among the two patient groups on both methods of measurement.

The 95\% limits of agreement (red dashed lines) are much wider for $\mathrm{Et}_{\mathrm{CO} 2}$ measurements, reflecting the higher values of the mean difference between $\mathrm{Et}_{\mathrm{CO} 2}$ and the venous blood gas. Notably, in Figure 3B, the 95\% confidence limits for the sampling error of the mean difference of $\mathrm{Et}_{\mathrm{CO} 2}$ versus $\mathrm{Pv}_{\mathrm{CO} 2}$ (blue dashed lines) do not include zero. This indicates that the mean bias in $\mathrm{Et}_{\mathrm{CO} 2}$ measurements is significantly different from zero $(P<0.05)$ for both NICU and non-NICU patients, as well as for the sample taken as a whole (see Table 3). In contrast, all the corresponding confidence intervals for $t \mathrm{P}_{\mathrm{CO} 2}$ measurements include zero, indicating lack of difference between tcP $\mathrm{P}_{\mathrm{CO} 2}$ and $\mathrm{Pv}_{\mathrm{CO} 2}$ measurements (see Figure $3 \mathrm{~A}$ and Table 3 ).

\section{Discussion}

The limits of agreement for both measurements were wide in both age groups. There are many physiological and 


\section{A}

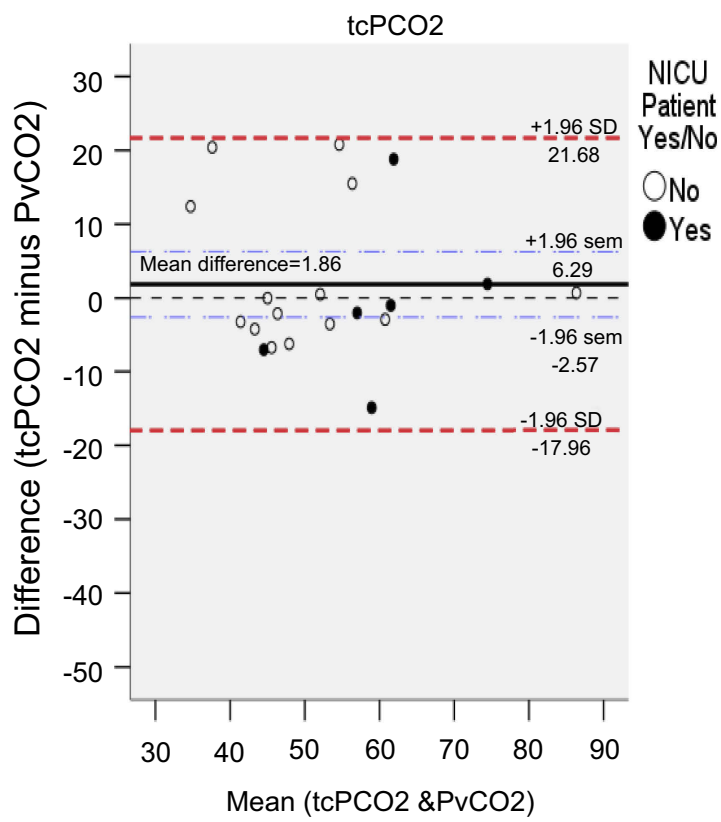

B

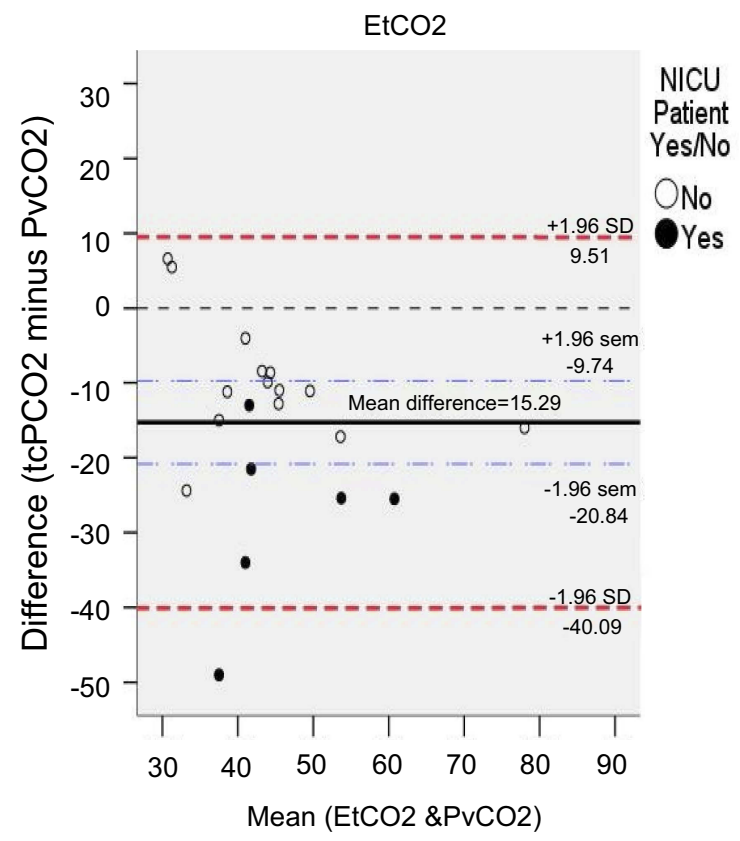

Figure 3 Bland-Altman plots showing mean difference (bias) for $\mathrm{tcP}_{\mathrm{CO} 2}$ (A) and $\mathrm{Et}_{\mathrm{CO} 2}$ (B) with $95 \%$ limits of agreement (red dashed lines). Blue dashed lines show the $95 \%$ confidence interval for the mean difference (bias). The bias is significant if the confidence interval does not include the line of equality (dashed line at zero). NICU patients, solid circles; non-NICU patients, open circles. Comparing tcP $\mathrm{PCO}_{\mathrm{CO}}$ to $\mathrm{Pv}_{\mathrm{CO} 2}$ (Figure $3 \mathrm{~A}$ ), these plots show good agreement between measures, with a mean difference (bias) of 1.86 , in the full sample of 20 patients. The $95 \%$ confidence interval for the mean difference (blue dashed lines) includes zero, indicating lack of meaningful difference between tcP $\mathrm{P}_{\mathrm{CO} 2}$ and $\mathrm{Pv}_{\mathrm{CO} 2}$ measurements comparing $\mathrm{Et}_{\mathrm{CO} 2}$ to $\mathrm{Pv}_{\mathrm{CO} 2}$ (B), the plots show a much higher bias of -15.29 for the full sample, with high variability, especially among NICU patients. Notably, in (B), the $95 \%$ confidence limits for the mean difference (blue dashed lines) do not include zero. This indicates that the mean bias in Et $\mathrm{CO}_{2}$ measurements is significantly different from zero $(P<0.05)$ for the sample taken as a whole.

Abbreviations: $\mathrm{PV}_{\mathrm{CO} 2}$, venous blood gas; $\mathrm{tcP}_{\mathrm{CO} 2}$, transcutaneous $\mathrm{CO}_{2}$; $\mathrm{Et}_{\mathrm{CO}}$, end-tidal $\mathrm{CO}_{2}$; $\mathrm{NICU}$, neo-natal intensive care unit.

iatrogenic changes during surgery which can alter $\mathrm{CO}_{2}$, and necessitates accurate $\mathrm{CO}_{2}$ values to assure proper ventilation in the operative care. The inaccuracy of $\mathrm{Et}_{\mathrm{CO} 2}$ in this population compelled this study of the agreement between the monitors and the $\mathrm{Pv}_{\mathrm{CO} 2}$. Since this study utilized children below $10 \mathrm{~kg}$, which encompasses both neonates and infants, we were able to study the effects of both $\mathrm{Et}_{\mathrm{CO} 2}$ and $\mathrm{TcP}_{\mathrm{CO} 2}$ on both populations. Our study found that $t c \mathrm{P}_{\mathrm{CO} 2}$ correlates better with $\mathrm{Pv}_{\mathrm{CO} 2}$ in younger children, specifically in the neonatal population.

With long-term ventilator management in neonates and infants with respiratory failure, $\mathrm{tcP}_{\mathrm{CO} 2}$ is a viable alternative to $\mathrm{Et}_{\mathrm{CO} 2}$ in the NICU. ${ }^{1}$ A more recent study demonstrated that $\mathrm{tcP}_{\mathrm{CO} 2}$ was correlated with venous $\mathrm{CO}_{2}$, although the study was limited by small sample size. ${ }^{10}$ In cases of infants with bronchiolitis, it was found that there was reasonable correlation between $\mathrm{tcP}_{\mathrm{CO} 2}$ and $\mathrm{Pv}_{\mathrm{CO} 2}$, but the investigators felt the monitor was to be used as an adjunct rather than as a primary monitoring tool. ${ }^{5}$ Longterm ventilator management in a larger study suggested moderate correlation of $\mathrm{tcP}_{\mathrm{CO} 2}$ with arterial $\mathrm{CO}_{2}$ levels, although bias was greater when transcutaneous monitoring was employed in HFOV. ${ }^{11}$ In addition, a recent study demonstrated poor correlation between $\mathrm{Et}_{\mathrm{CO} 2}$ and $\mathrm{Pv}_{\mathrm{CO} 2}$ in anesthetized neonates for general surgery. ${ }^{12}$ Similar effects have been noted for $\mathrm{Pa}_{\mathrm{CO} 2}$ as well. ${ }^{13}$ This is the same effect noted in our study; however, we were able to demonstrate improved agreement between $\mathrm{Pv}_{\mathrm{CO} 2}$ and $\mathrm{tcP}_{\mathrm{CO} 2}$ during the perioperative period as compared to $\mathrm{Et}_{\mathrm{CO} 2}$.

Our study was limited to the perioperative period; however, the NICU literature suggests decreasing correlation with $\mathrm{Pv}_{\mathrm{CO} 2}$ with long-term mechanical ventilation. ${ }^{11}$ This suggests that in the short term, the utility of having a single accepted, correlated monitor for both the OR and the NICU cannot be overstated. Further, larger studies are needed to validate $\mathrm{tcP}_{\mathrm{CO} 2}$ as a stand-alone monitor, specifically for acute events resulting in large $\mathrm{CO}_{2}$ shifts, such as an accidental or intentional extubation, endobronchial intubation, or mucus plugging, which are seen in the intraoperative period. Answers to these questions require a greater number of neonates across a greater spectrum of surgeries. Specifically, surgeries in which there are greater shifts of $\mathrm{CO}_{2}$ including those with abdominal insufflation 
Table 3 Results of Bland-Altman analyses individually comparing tcP $\mathrm{P}_{\mathrm{CO} 2}$ and $\mathrm{Et}_{\mathrm{CO} 2}$ to $\mathrm{Pv}_{\mathrm{CO} 2}$. All measures were taken at the end of the surgery, as close as possible to the time of venous blood sampling. Values shown are bias (mean difference), the standard deviation (SD) of the bias, and $95 \%$ limits of agreement (mean $\pm 1.96 * \mathrm{SD}$ ). Also shown is the standard error of the mean (sem), which is the basis for calculation of the confidence interval $(\mathrm{Cl})$ for the sampling error of the mean (mean $\pm 1.96 *$ sem)

\begin{tabular}{|c|c|c|}
\hline Group & $\mathrm{TcP}_{\mathrm{CO} 2}$ vs $\mathrm{Pv}_{\mathrm{CO} 2}$ & $\mathrm{Et}_{\mathrm{CO} 2}$ vs $\mathrm{Pv}_{\mathrm{CO} 2}$ \\
\hline \multicolumn{3}{|l|}{$\operatorname{NICU}(n=6)$} \\
\hline Bias & -0.70 & -28.07 \\
\hline Bias SD & 11.23 & $|2.3|$ \\
\hline $95 \%$ limits & $-22.7 \mid$ to $21.3 \mid$ & -52.20 to -3.94 \\
\hline Bias sem & 4.58 & 5.02 \\
\hline $95 \% \mathrm{Cl}$ for mean & -9.68 to 8.28 & -37.91 to $-18.23 *$ \\
\hline \multicolumn{3}{|l|}{ Non-NICU $(n=14)$} \\
\hline Bias & 2.96 & -9.82 \\
\hline Bias SD & 9.83 & 8.26 \\
\hline $95 \%$ limits & $-16.3 \mid$ to 22.23 & -26.01 to 6.37 \\
\hline Bias sem & 2.63 & 2.21 \\
\hline $95 \% \mathrm{Cl}$ for mean & -2.19 to 8.11 & -14.15 to $-5.49 *$ \\
\hline \multicolumn{3}{|l|}{ Total sample $(n=20)$} \\
\hline Bias & 1.86 & -15.29 \\
\hline Bias SD & 10.11 & 12.66 \\
\hline $95 \%$ limits & -17.96 to 21.68 & -40.09 to 9.51 \\
\hline Bias sem & 2.26 & 2.83 \\
\hline $95 \% \mathrm{Cl}$ for mean & -2.57 to 6.29 & -20.84 to $-9.74 *$ \\
\hline
\end{tabular}

Notes: $* 95 \% \mathrm{Cl}$ does not include zero, indicating that measurements are significantly $(P<0.05)$ different from zero.

Abbreviations: $\mathrm{PV}_{\mathrm{CO} 2}$, venous blood gas; $\mathrm{tcP}_{\mathrm{CO} 2}$, transcutaneous $\mathrm{CO}_{2}$; $\mathrm{Et}_{\mathrm{CO} 2}$, end-tidal $\mathrm{CO}_{2}$; NICU, neo-natal intensive care unit.

(laparoscopy), neurosurgery with $\mathrm{CO}_{2}$ manipulation to influence cerebral blood flow, and lengthy surgeries would benefit from an additional monitor with a stronger agreement with $\mathrm{PV}_{\mathrm{CO} 2}$. This, in theory, would allow for a non-invasive calculation of $\mathrm{M}_{\mathrm{vO} 2}$ (mixed venous oxygen saturation) provided that $\mathrm{Pa}_{\mathrm{O} 2}$ is either known or calculated from the $\mathrm{Sp}_{\mathrm{O} 2}$.

One drawback of this study was the inability to obtain $\mathrm{Pv}_{\mathrm{CO} 2}$ at the end of the surgery in all patients. This was due to a combination of difficult intravenous or heel sticks, vasoconstriction, and in some cases inadequate sample which was discovered only after the patient had left the OR.

\section{Conclusions}

End-tidal $\mathrm{CO}_{2}$ underestimates venous blood gas $\mathrm{CO}_{2}$ values in NICU and infant patients completing surgery.
Transcutaneous $\mathrm{CO}_{2}$ closely agrees with venous blood gas values, in both the NICU and non-NICU sample, but more closely in NICU patients. We conclude that transcutaneous $\mathrm{CO}_{2}$ is a more accurate measure than $\mathrm{Et}_{\mathrm{CO} 2}$ of venous blood $\mathrm{CO}_{2}$ levels in both NICU patients and infants. We postulate that utilizing $\mathrm{tcP}_{\mathrm{CO} 2}$ values will improve the ability to effectively guide ventilation in this population during operative care.

\section{Quick look}

Current Knowledge: Transcutaneous $\mathrm{CO}_{2}$ has not been compared in the neonatal and infant perioperative population with $\mathrm{Et}_{\mathrm{CO} 2}$.

What this paper contributes to our knowledge: The study demonstrates that transcutaneous $\mathrm{CO}_{2}$ is better correlated with the venous $\mathrm{CO}_{2}$ than standard $\mathrm{Et}_{\mathrm{CO} 2}$ in younger and smaller infants, specifically NICU patients.

\section{Ethics}

This study was approved by the Stony Brook University Committee on Research Involving Human Subjects (IRB), 5 August 2014, Ref. \#2014-2629-R3. This study was performed in accordance with the Declaration of Helsinki.

\section{Acknowledgments}

We thank Derek Nelsen MD, Faraz Khan MD, Alexander Praslick MD, and Stephanie Waring BS, Cert.AT., for their assistance in collecting the data. SenTec supplied monitor, disposables and technical support. For all other costs, the study was funded by departmental resources. This research was performed at Stony Brook University Hospital, Stony Brook, NY. This research was previously presented by Dr. Khmara at the Society for Pediatric Anesthesia, 2017, and was the winner of the AAP Award for Best Resident Research Award.

\section{Disclosure}

SenTec continues to support Dr Seidman's research with monitors, disposables and technical support. She is on their clinical advisory board for which she receives no monetary compensation. Dr Peggy Seidman reports nonfinancial support from SenTec, during the conduct of the study; non-financial support from SenTec outside the submitted work. The authors report no other conflicts of interest in this work. 


\section{References}

1. Tobias JD, Meyer JD. Noninvasive monitoring of carbon dioxide during respiratory failure in toddlers and infants: end-tidal versus transcutaneous carbon dioxide. AnesthAnalg. 1997;85:55-58.

2. Wilson J, Russo P, Russo J, Tobias JD. Noninvasive monitoring of carbon dioxide in infants and children with congenital heart disease: end-tidal versus transcutaneous techniques. $J$ Int Care Med. 2005;20:291-300. doi:10.1177/0885066605278652

3. Tobias JD. Noninvasive carbon dioxide monitoring during one-lung ventilation: end-tidal versus transcutanous techniques. $J$ Cardiothorac Vasc Anesth. 2003;17:306-308.

4. Tobias J. Transcutaneous carbon dioxide monitoring in infants and children. Ped Anes. 2009;19:434-444. doi:10.1111/j.1460-9592.2009. 02930.x

5. Gal S, Riskin A, Chistyakov I, Shifman N, Srugo I, Kugelman A. Transcutaneous $\mathrm{P}_{\mathrm{CO} 2}$ monitoring in infants hospitalized with viral bronchiolitis. Eur J Ped. 2015;174(3):319-324. doi:10.1007/s00431014-2407-2

6. Nangia S, Saili A, Dutta AK. End tidal carbon dioxide monitoring - its reliability in neonates. Ind J Ped. 1997;64:389-394. doi:10.1007/ BF02845211
7. Nosovitch MA, Johnson JO, Tobias JD. Noninvasive intraoperative monitoring of carbon dioxide in children: endtidal versus transcutaneous techniques. PaediatrAnaesth. 2002;12:48-52.

8. Bland JM, Altman DG. Statistical methods for assessing agreement between two methods of clinical measurement. Int J Nursing Studies. 2010;47:931-936. (Reprinted from The Lancet 1986; 327(8476):307310.). doi:10.1016/j.ijnurstu.2009.10.001

9. Giavarina D. Understanding Bland Altman analysis. Biochemia Medica. 2015;25(2):141-151. doi:10.11613/BM.2015.015

10. Karlsson V, Sporre B, Ågren J. Transcutaneous $\mathrm{P}_{\mathrm{CO} 2}$ monitoring in newborn infants during general anesthesia is technically feasible. Anesth Analg. 2016;123(4):1004-1007. doi:10.1213/ANE.0000000000001462

11. Mukhopadhyay S, Maurer R, Puopolo KM. Neonatal transcutaneous carbon dioxide monitoring-Effect on clinical management and outcomes. Resp Care. 2015; respcare.04212. doi:10.4187/respcare.04212

12. Karlsson V, Sporre B, Hellström-Westas L, Ågren J. Poor performance of main-stream capnography in newborn infants during general anesthesia. Ped Anes. 2017;27:1235-1240. doi:10.1111/pan.13266

13. Trevisanuto D, Giulliotto S, Cavallin F, Doglioni N, Toniazzo S, Zanardo V. End-tidal carbon dioxide monitoring in very low birth weight infants: correlation and agreement with arterial carbon dioxide. Pediatr Pulmonol. 2012;47(4):367-372. doi:10.1002/ppul. 21558
Medical Devices: Evidence and Research

\section{Publish your work in this journal}

Medical Devices: Evidence and Research is an international, peerreviewed, open access journal that focuses on the evidence, technology, research, and expert opinion supporting the use and application of medical devices in the diagnosis, monitoring, treatment and management of clinical conditions and physiological processes. The identification of novel devices and optimal use of existing devices

\section{Dovepress}

which will lead to improved clinical outcomes and more effective patient management and safety is a key feature of the journal. The manuscript management system is completely online and includes a very quick and fair peer-review system. Visit http:// www.dovepress.com/testimonials.php to read real quotes from published authors. 